\title{
Childhood Burkitt Lymphoma
}

National Cancer Institute

\section{Source}

National Cancer Institute. Childhood Burkitt Lymphoma. NCI Thesaurus. Code C9095.

A Burkitt lymphoma occurring in children. 